\title{
A Psychogenesis of Color-Based Racism: The Implications of Colonialism for People of Color
}

\author{
Ronald E. Hall \\ Michigan State University, East Lansing, USA. \\ Email: hallr@msu.edu \\ Received July $9^{\text {th }}, 2010$; revised March $2^{\text {nd }}, 2011$; accepted April $7^{\text {th }}, 2011$.
}

\begin{abstract}
Influenced by European colonization people of color have internalized a disdain for dark skin i.e.: color-based racism. In addition to the historical literature and litigation color-based racism is here substantiated empirically. The contingency coefficient reflected a moderate correlation between the variables, therefore the null hypothesis was rejected and the research hypothesis was accepted. To educate Psychologists about the significance of color-based racism among people of color will require an acknowledgement of its existence. In the aftermath, people of color and the practitioners who serve them will move Psychology to the next level of service technology.
\end{abstract}

Keywords: People of Color, Skin Color, Racism

\section{Introduction}

Influenced by Western i.e.: European colonization people of color including African-, Asian-, Latino- and Native-American (Indians) descent have internalized a disdain for dark skin (Agier, 1995). The existence of such disdain is historical and immune to dispute in the aftermath of color-based racism as European colonial influence. Without exception, European colonialism is an environmental force that disrupts the well-being of universal social discourse. Although the Psychology literature minimally acknowledges color-based racism among people of color, amidst a Western obsession with race the neglect of color-based racism has been all but institutionalized (Solomon, 1992). Greater focus on skin color would enhance the ability of Psychology academics and practitioners to purge racism from social discourse thereby reducing its various forms of oppression (Hall, 2006).

The objective of this paper is to inform. It will offer the Psychology readership and interested social science scholars insight to some of the post-colonial challenges which continue to prevail upon the psyches of people of color. It will accommodate understanding of what people of color encounter as a form of color-based racism often perpetrated and perpetuated by their lighter-skinned counterparts. The lighter-skinned counterpart is a subjective, self prescribed hue closer in proximity to White than the typical native hue. It is in affect a vehicle of colorbased racism. Attention to color-based racism is designed to enhance understanding of the unique blend of cultural experiences and behavioral dynamics involving colonial influence of the non-European population at-large-in particular those who reside in Western and/or European nations. This paper will also provide a framework for objectively differentiating the life experiences encountered by people of color otherwise irrelevant to their emotional and psychological well-being.

\section{Western Colonization}

Racism relative to Western colonization is regarded in aca- deme as an extension of "white supremacy" (Hopkins, 1980). In a social sciences context, racism, according to Banton (cf. Kitano, 1985), refers to the efforts of a dominant race group to exclude a dominated race group from sharing in the material and symbolic rewards of society. It differs from other forms of exclusion in that qualification is based upon race implied by skin color and other observable racial characteristics. Such characteristics are taken to suggest the inherent superiority of the dominant race group, which is then rationalized as a natural order of the biological universe (Minor \& McGauley, 1988).

The most zealous proponents of racism profess that lightskinned Anglo-Saxon/Teutonic people are superior to the darkskinned as a matter of biological fact (Welsing, 1970). They postulate that Caucasian race people i.e.: of European descent have been uniquely endowed with the capacities necessary to bring about civilization. Their so-called "advancing civilization" was a cultural form of oppression devoted to rationalizing the right of Caucasian race people to embark upon a mission aimed at dominating their dark-skinned subordinates as rationale for colonization (Pinderhughes, 1982; Daly, Jennings, \& Leashore, 1995). By way of conquest, slavery and/or colonization, Western European Caucasians eventually influenced every society of the known world. In the wake of colonization, the mission to "civilize" non-Europeans including people of color necessitated a universal belief in the potency of race idealized by skin color to elevate or taint (Hyde, 1995). In the post-colonial era people of color have internalized colonial ideals apparent in color-based racism.

As pertains to Western colonization racism is defined as the peopling of foreign territory previously settled by a native population with emigrants from the mother country (Kitano, 1997). Among the most active relative to colonial nations have been Spain, Great Britain, and Portugal, etc. Since the existence of the West's Roman Empire, colonial powers have dealt with their subjects in one of three ways: eradication, exclusion or assimilation (Powell, 1997). Germane to the implications of colonization for color-based racism is assimilation. The psychological trauma and brutality suffered by people of color 
during assimilation as per the colonial experience has not been resolved. Previous European colonies are now proud, independent sovereign nations but the effects of colonization remain. The idealization of light skin and other European qualities is ever visited upon the post-colonized psyche. While it is less violent than traditional colonization, psychologically postcolonization is no less brutal in the way that it demeans people of color. Ironically it is the assimilation experience and other Western influences encountered by people of color that has impacted their self-concept manifested in the post-colonial era as color-based racism directed at same.

\section{Color-Based Racism}

The most convincing implications of skin color for colorbased racism among Native-American Cherokee Indians are couched in history. The Cherokee tribes in particular were not the savages they had been made out to be by colonial scholars. They maintained a National Council that was controlled by educated, tribesmen, many of whom adhered to the value system of slave traders. They set up schools, which were modeled after same, where colonial values could be passed on to youth. In many instances, it was the dark-skinned "full-blood" Cherokee, who were a minority within such groups. The primary objective was the "refinement" of girls so that they might serve as dutiful wives in the Cherokee Nation. Another interest was in the assimilation of the darker-skinned, "full-blood" Cherokee girls, but apparently, this idea did not come about until 1871, by disgruntled tribesmen to establish a department to provide education free of charge to poorer, darker-skinned "full-bloods" (Halliburton, 1977).

While it was true that many Cherokee were from affluent lighter-skinned families, the very wealthy were in the minority. The majority could pay tuition, but they were not necessarily from among the nation's upper class. In fact, daughters of such families frequently attended schools outside the Cherokee Nation. And each year, dozens of dark-skinned "full-bloods" went to the school free of charge. Later (1851 - 1856) a class system at some of the schools was based on wealth, but from 1872 until 1910, status was based more on skin color as implied by race (Cherokee and white blood quantums), appearance (Native or Caucasian), and degree of assimilation (Halliburton, 1977).

Certain individuals among the Cherokee students and teachers took pride in their light skin. Students frequently taunted those who had less "white" blood and darker skin. A few of the "full-bloods" also scorned those who had limited knowledge of Western ways. It was generally assumed among the mixedblood students that the "full-bloods" were "a little bit backward," and that the dark-skinned "full-bloods" were well aware of their inferior status. The sentiment for skin color learned via Western colonization had gained significant momentum.

The preference for light skin among people of color is a psychological manifestation of color-based racism no less relevant in recent history, even though light skin among many people of color is less common than the relative dark (Hall, 1995). Value-laden folk terms evolved among African-Americans that reflect the fact, such as folk references to "high-yellow," "ginger," "cream-colored” and "bronze” (Herskovits, 1968). When the term "black" is used, it more often infers something derogatory (Hall, 1990). However having light skin did not assure bliss as in the life of African-American actress Dorothy Dandridge.

In real life Dorothy Dandridge was a light-skinned AfricanAmerican who exemplified the ultimate metaphor of "tragic mulatto" in the failings of her film career. The light-skinned attributes which may have enabled her professionally may have forced her to live out a screen image that eventually destroyed her. Rumor has it she succumbed to alcoholism, drugs, and destructive love affairs. Finally in 1965, at the age of forty-one, Dorothy Dandridge was found dead, the victim of an overdose of anti-depression pills. The tragedy of Dandridge's life is that as a light-skinned African-American ashamed of being Black light skin denied her the possibility of fulfillment either as completely Black or completely White despite White being the ideal.

In a culture where race dominates, persons acquire self-worth extended from their racial proximity to White as an identity. Such identification with White, while not universally compulsive, enables them to define self in social terms. What those in the UK may say to themselves and to others is: "I am not Black; I am biracial; I belong; I am.” Hence in a post-colonial environment the measure of self-worth and confidence will be largely dependent upon the social assessment and personal satisfaction/frustration inherent in racial identifications (Wade, 1996).

Similar to America, the biracial Briton connoted actuality of the "tragic mulatto," but that has surely changed (Russell, Wilson, \& Hall, 1992). For the first time in recent history the "one drop theory”, does not predetermine same as solely Black. But deserting the racial paradigm may mean correcting others in that one is biracial. The process begins with the very first encounter where biracial Britons challenge race rhetoric and continues throughout life, decreasing only to the extent they are consistently identified with other than their assigned race category.

The need of biracial Britons for a more comprehensive identity paradigm contrasts with the degree to which race remains imperative. While numbers may be few, those who prefer to distance themselves from certain aspects of their dark-skinned racial heritage must-for psychological reasons-have the option to do so. This perspective is counter to the notion of racial paradigms that define identity as rooted in phenotype and realized at a biologically determined point in maturation. But for the light-skinned biracial Briton, imperatives remain, rendering other than race based paradigms questionable. The dynamic is complex because legitimate identity does in fact exceed the bounds of its racial context. As a result, being light-skinned may be assumed relevant and responsive to circumstances, history, and culture. But tradition allows for the validation of racial paradigms in mythic proportion (Hall, 1993). Racial implications for identity, no doubt, inhibit fluidity causing it to be rigid and/or less malleable. In the aftermath, race is inculcated by pop-scholars who perpetuate hegemony and the unnecessary trivialization people of color in Britain silently endure.

Wearing a thin guise of fiction, a British Asian actress in the movie "Mississippi Masala" dramatized color-based racism before the world in 1992. In a seeming anomaly of the Hindu caste system, the lowest among East Indians may discriminate against dark-skinned minorities of higher status. This would be 
the grist of black comedy if it were not so tragic. Among Indian Asians light skin is believed to shape the lives of common folk and those of the people they live, love, and work with. Many have only a vague conception of that hereditary and restrictive-but somewhat adaptive-institution that is Hindu caste, and suppose only that at any given level, color and caste are coordinated with those at the top-privileged and light-skinned -and those at the bottom-destitute, very dark-skinned, and much discriminated against (Hall, 1994).

Perhaps the most psychological damage from color-based racism is visited upon women of color. Those in Pakistan aspire to light skin by bleaching themselves. One such woman is a well educated 23 year-old named Nasim Jamil (IRIN, 2004). While she is young and attractive she is not at all satisfied with the way she looks. "I am not fair enough," she commented to a local news organization. She further maintains that "White is best. When you ask Pakistani ladies what their idea of an ideal woman is, they will tell you that she should have fair skin.” This is fact according to Fozia Yasmin who works for the Pakistani nongovernmental organization who reported to the IRIN news organization. There are at least 50 percent of women Ms. Yasmin has encountered who have sought her out for concerns about their skin color. As women who reside in an Islamic nation they are expected to look their best without exception while simultaneously being required to be subservient to men (IRIN, 2004).

Fair skin is considered an asset in India, says Rachna Gupta who is a 38-year-old part-time interior designer (Leistikow, 2003). Considering this about once a month, she visits her local beauty salon in south Delhi for an application of Jolen Creme Bleach. The package states that it "lightens excess dark hair" but Rachna has it applied to her face to affect lighter skin. "It's not good for the skin," she insists, "but I still get it done because I am on the darker side and it makes me feel nice. Aesthetically, it looks nice" (Leistikow, 2003).

In Canada a 16-year-old woman of color who is a student named Grace gets up in the morning and while standing in front of the mirror is hurt by what she sees as herself (Obaahema Network, 2002). The image that is reflected in the mirrors is one which causes her to be severely depressed. She does not like her kinky-permed-straight African hair in a world where almost all hair is straight. Her nose is broad and her lips are thick in a world where noses are keen and lips thin. Her dark brown eyes suggest she is ugly and having no way to escape resorts to applying bleaching creams to her skin. Each time she resorts to the bleaching creams is an opportunity to escape her ugliness. With each application she can approach the escape from her dark ugliness and get closer to the idealized lightskinned Western colonial beauty. When the cream wears off Grace is forced to acknowledge the fact that she is Black. She must admit that she is undesirable to men and only by bleaching to lighten her skin can she be rescued from her fate. She believes her failure to bleach will sentence her to a life of horror and shame in her dark skin (Obaahema Network, 2002).

Another woman of color named Latoya is a 17-year-old Jamaican who is determined to bleach her skin which the locals call "brownin" (Obaahema Network, 2002). "Brownin is a Jamaican term used all over the Caribbean island in reference to Blacks who have light skin. Latoya applies thick layers of bleaching creams to her face despite the fact that some may contain dangerous steroids. She is aware that the warning labels advise her that the practice of bleaching could damage her skin. Without concern she goes about daily bleaching because she is pleased with what she sees of herself. "When I walk on the streets you can hear people say, 'Hey, check out the brownin'. 'It is cool. It looks pretty',” This Latoya wants more than anything else. "When you are lighter, people pay more attention to you. It makes you more important” (Obaahema, 2002).

In more extreme reactions to skin bleaching African women incur increased risks to their health leading to the disruption of organ performance. "There is suspicion of an increased risk of renal failure as a result of the mercury contained in some of the products that people use for bleaching," according to African Dr. Doe (Opala, 2001). Unfortunately too many women who bleach do not seek medical help until it's too late. This has spurred an effort on the part of doctors to promote public service announcements in hopes of educating the public to the dangers of bleaching. The extent of such persons in Africa is becoming so widespread that some of the governments are beginning to exercise caution. For example in Gambia, the government has decided to outlaw all skin-bleaching products including Bu-Tone, Madonna Cream, Glo-Tone, and the American-made Ambi. They decided to be lenient on those caught with bleached skin. Furthermore officials in Europe have also begun to take issue with the practice as Denmark has also banned skin bleaching creams and soaps. Officials there have traveled to a number of local African shops and gathered up the products. Unfortunately, Tura, which is a product outlawed by Danes is still popular in Ghana and other African countries. While the business community may find these actions extreme, doctors concur that they're not without reason (Opala, 2001).

Among Latinos in America color-based racism has been documented in U.S. courts. One of the first cases was that of the dark-skinned Felix-plaintiff_-versus the lighter-skinned Marquez-defendant. It was litigated in 1981. Both plaintiff and defendant were employees of the same government office. The plaintiff alleged that the defendant did not promote her on the basis of skin color discrimination. At trial, the plaintiff introduced the personnel cards of twenty-eight of her former fellow employees. She testified that among them, only two were as dark as or darker in color than she. All of the other employees in the office, according to the plaintiff, were light-skinned. The court ruled in favor of the defendants (District of Columbia, 1981). However it should be noted that validation of color-based racism as an issue among Latinos is reflected in charges brought regardless of ability to prevail. In addition to litigation such color-based racism is here established empirically among African-Americans as well.

\section{Method}

A list of prospective students was obtained from the registrar's office. From that list participants were randomly selected resulting in the required 200 students. To maintain anonymity, their names were converted into numerical codes and all data was reported in the aggregate.

The statistical procedure involved correlation between the independent and dependent variables. Thus the chi square was applied to determine whether frequency occurred by chance and the coefficient contingency was applied as a test of correlation 
on nominal data.

Using a sample of African-American college freshmen the following null hypotheses were formulated to provide an objective basis for investigating the issue of color-based racism among people of color. The .05 level of significance was used as criterion of acceptance or rejection of the null and research hypotheses.

H0: There is no significant relationship between self-identified skin color and light skin as ideal for a selected sample of African-American college freshmen.

H1: There is a significant relationship between self-identified skin color and light skin as ideal for a selected sample of African-American college freshmen.

By way of empirical analysis of the objective, it is hoped that the findings will offer a fresh perspective on the psychogenesis of color-based racism among people of color.

\section{Sample}

The sample for this study included 200 African-American, first-year students attending a historically Black college located in south Georgia, USA during the traditional academic school year. They were randomly selected from the registrar's roster. Respondents had a mean age of 18 years (SD $=0.88$ ). All were attending college full-time and classified as regularly admitted students. A self-report instrument was utilized for measuring their skin color. This method-instead of an in-depth interview-was assumed by the investigator to more accurately reflect the significance of skin color in color-based racism.

\section{Measures}

The self-report instrument is called the Cutaneo-ChromaCorrelate (CCC). It was developed and validated by the author to assess the relationship-if any-between skin color and its idealized qualities. Part B of the CCC assesses the respondent's personal values pertaining to skin color (see Table 1). In scoring a student's responses, a rating of lightest was coded as a 5 , light as a 4 , medium as a 3 , dark as a 2 , and darkest as a 1 concluding in nominal data.

The self-identification of skin color served as the independent variable addressed through item \#35 (My skin color is__ ( The rating of ideal as pertains to light skin was addressed through item \#20 (Pretty skin is___ It served as the dependant variable. The entire CCC was pilot tested prior to use in this study (Hall, 1990).

\section{Research Design}

The respondents were divided into two groups based on their self-reported skin color, light vis-à-vis "lightest” or "light” and dark vis-à-vis “dark" or "darkest.” The nominal status of the self-ratings limited the method of data analysis. Those rating themselves as "lightest" or "light" composed the light group (n = 57). Those rating themselves as "dark" or "darkest" composed the dark group $(n=26)$. The numerical values of the five possible responses to item \#35 (My skin color is___) and item \#20 (Pretty skin is___ ) were used to calculate the correlation between self-reported skin color and selected values for the ideal. A significant correlation $(\mathrm{p}<.05)$ was assumed to suggest light skin as ideal and evidence of color-based racism.

\section{Results}

The greatest frequency in the high and low categories was reported for the light and dark groups. When means were compared, the higher mean was obtained by the light group. The Chi square obtained (14.43, $\mathrm{d} f=1$ ) exceeded the critical value required to be significant beyond the .05 level for a two-tailed test. In as much as the Chi square was significant, the $C(.5102)$ was also significant. The attained contingency coefficient however reflected a moderate correlation between the variables, therefore the null hypothesis was rejected and the research hypothesis was accepted (There is a significant relationship between self-identified skin color and light skin as ideal for a selected sample of African-American college freshmen).

\section{Discussion}

A substantial portion of social science research suggests that the perception of another person's skin color may consciously or subconsciously elicit certain assumptions, expectations, and interpersonal responses on the part of an observer (Hall, 2004). Due to the fact that race vis-à-vis skin color is such a primal component of one's personal worth, comprehension of the psychological implication is critical. If those who embrace Psychology are to understand people of color, understanding the post-colonial implications of skin color will be imperative to the assessment and ultimate resolution of their presenting problem. On the other hand, pathologies can occur when responses to others are grounded in skin color alone or when color-based assumptions and stereotypes do not concur with and dominate personal talents, abilities and other characteristics.

Table 1.

Identity and skin color ideal.

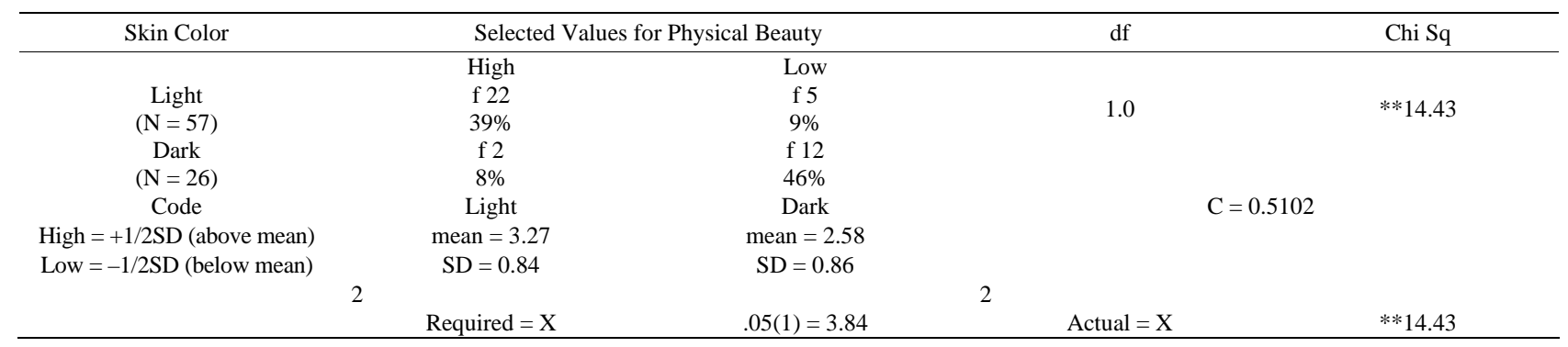

$* \mathrm{p}<.05 ; * * \mathrm{p}<.01$ 
Under such circumstances skin color applied without context compromises the accuracy of practice and human perceptions.

Diversity in Psychology and those concerned with bringing about more comprehensive treatment methods for people of color initiated the attention to their many negative helping experiences (Urrutia, 1994). Consequently, the attention to skin color herewith extends from and is rooted in such concerns. Accordingly, the current objective is illumination of skin color as pertains to implications for the field of Psychology involving individuals, groups, and families. In the aftermath enables exploration of skin color not only as an issue among people of color, but also in terms of its implications for Psychology's practitioners. Skin color has implications for people of color and practitioners regardless of race, skin color or practice skill level. Empirical evidence correlates skin color with education, occupation, income, beauty, and health, etc. (Hall, 2000). While clients seek the attention of service providers service providers as practitioners are not immune to the correlations of skin color which they bring to the helping process. Although the emphasis of this paper is devoted to people of color the implications of skin color for the field of Psychology must be acknowledged as a universal helping issue. To enable more effective practice with people of color it will be helpful to:

* determine the class, social and familial circumstances of the client

* be sensitive to the possibility that people of color who are in crisis or who are experiencing powerful emotions may have issues with the skin color of the Psychologist or self aside from race

* seek relevant support systems if such action seems appropriate

* review the literature pertaining to the history and traditions of Western colonization

\section{Conclusion}

The historical facts and empirical research pertaining to people of color leave no doubt as to the significance of color-based racism in their lives. In business professions, in the arts at the university, and the Psychology profession it is obvious that most of those involved are of European descent among whom, skin color aside from race is a less salient issue (Bonila-Silva, 1991). Whatever the root of differentiation between client and practitioner, be it racism, socialization, or a simple lack of exposure Psychology is rendered less affective by said differentiation.

The validation of skin color differences between and among people of color is inevitable. Scientists believe that skin color is incorporated into human definitions of self and awareness of others by the time they reach the age of three (Clark \& Clark, 1980). Where adults are concerned, the perception of skin color is inclined to be significant for processing personal information. In most circumstances when persons encounter one another based upon skin color they assign color categories and then attempt to apply some rational order to what fits and what does not. It is not necessarily a conscious effort used by professionals or the general population. The process involves any combination of race and skin color between practitioner and client, practitioner and practitioner and client and client. However the issue is much more salient as pertains to people of color (Hall,
2003).

To educate Psychologists about the significance of colorbased racism among people of color will require an acknowledgement of its existence. It has up to the present been overlooked on the basis of cultural taboos and maintaining polite social discourse. Some of the taboos include assumed differences which are little more than myth. By disqualifying said myths from polite conversation in fact sustains the difficulty encountered by people of color during the practice situation.

The limitations of the current study included sample size, race, and geographic location. People of color comprise several different racial and ethnic groups. The 200 participants selected from among African-Americans located at a southern U.S. institution of higher education increases the risks of error in that other people of color from other locations may think differently.

Lastly, acknowledgement of color-based racism minimizes the potential for conflict and complies with the genesis of a new awareness in Psychology and/or practice. It is increasingly evident that at least among people of color skin color is pertinent to the study of self-image, self-esteem, family dynamics, etc. Its acknowledgement is a necessity in a world fast becoming not only racially indistinct but ethnically and culturally indistinct as well. The subsequent diversity in the ethos of Psychology has facilitated assertions on the part of people of color to value them. Their findings have validated the colonial importance of skin color and other native issues as having a direct association with psychological well-being. In the aftermath, people of color and the practitioners who serve them will move Psychology to the next level of service technology.

\section{References}

Agier, M. (1995). Discrimination, culture and black identity in Brazil. Bulletin of Latin American Research, 14, 245-264. doi:10.1111/j.1470-9856.1995.tb00010.x

Bonilla-Silva, E. (1991). The essential social fact of race. American Sociological Review, 64, 899-906. doi:10.2307/2657410

Clark, K., \& Clark, M. (1980). Skin color as a factor in racial identification of Negro pre-school children. Journal of Social Psychology, 11, 159-169. doi:10.1080/00224545.1940.9918741

Daly, A., Jennings, J., Beckett, J., \& Leashore, B. (1995). Effective coping strategies of African Americans. Psychology, 40, 40-48.

District of Columbia (1981). Felix vs. Marquez. United States Court of Appeals, 78-2314.

Germaine, C. (1991). Human behavior in the social environment: An ecological perspective. New York, Columbia University Press.

Halliburton, R. (1977). Red over black: Black slavery among the Cherokee Indians. Westport: Greenwood Press.

Hall, R. (2006). The bleaching syndrome: Manifestations of a post-colonial pathology among African women. The Nigerian Journal of Guidance and Counseling, 11, 1-13.

Hall, R. (2004). The scientific fallacy and political misuse of the concept of race. Lewiston, NY: Mellen Press.

Hall, R. (2003). Discrimination among oppressed populations. Lewiston, N.Y.: Mellen Press.

Hall, R. (2000). A descriptive analysis of skin color bias in Puerto Rico: Ecological applications to practice. Journal of Sociology \& Social Welfare, 27, 171-183.

Hall, R. E. (1995). The bleaching syndrome: African Americans' response to cultural domination vis-a-vis skin color. Journal of Black Studies, 26, 172-183. doi:10.1177/002193479502600205

Hall, R. E. (1994). The bleaching syndrome: Light skinned, psychic conflict and the domination model of western assimilation. The In- 
dian Journal of Psychology, Tata Institute of Social Sciences, 55, 405-418.

Hall, R. E. (1993). Clowns, buffoons, and gladiators: Media portrayals of African-American men. The Journal of Men's Studies, 1, 239-251. doi:10.3149/jms.0103.239

Hall, R. E. (1990). The projected manifestations of aspiration, personal values, and environmental assessment cognates of cutaneo-chroma (skin color) for a selected population of African Americans. Ph.D. Thesis, Atlanta: Atlanta University, 1989. Dissertation Abstracts International, 50, 3363A.

Herskovits, M. (1968). The American Negro. Bloomington: Indiana University Press.

Hopkins, T. (1980). A conceptual framework for understanding the 'isms'-racism, ageism, sexism. Journal of Education for Psychology, 16, 63-70.

Hyde, C. (1995). The meanings of whiteness. Qualitative Sociology, 18, 87-95. doi:10.1007/BF02393197

IRINNEWS.ORG. (2004). Pakistan focus on skin bleaching. UN Office of Humanitarian Affairs. URL (retrieved 25 October 2009) http://www.irinnews.org/report.aspx?reportid=18174\#

Kitano, H. (1997). Race relations. New Jersey: Prentice-Hall.

Kitano, H. (1985). Race relations (3rd ed.). Englewood Cliffs, NJ: Prentice-Hall.

Leistikow, N. (2003). Indian women criticize "fair and lovely" ideal. India: Women's News.

Minor, N., \& McGauley, L. (1988). A different approach: Dialogue in education. Journal of Teaching in Psychology, 2, 127-140.
Obaahema Network. (2002). Effects of skin bleaching. URL (retrieved 25 October 2009)

http://www.obaahema.com/Channels/health_fitness/article.cfm?Artic leID $=7$

Opala, K. (2001). Cosmetics ban: Did standards body err? URL (retrieved 12 April 2003)

http://allafrica.com/stories/printable/200105290458.html.

Pinderhuges, E. (1982). Black geneology: Self liberator and therapeutic tool. Smith College Studies in Psychology, 52, 93-106. doi:10.1080/00377318209516554

Powell, A. (1997). Through my grandfather's eyes: Ties that bind. National Conference of African American Studies and Hispanic and Latino Studies. Houston, in press.

Russell, K., Wilson, M., \& Hall, R. E. (1992). The color complex: Last taboo among African Americans. New York: Harcourt Brace Jovanovich.

Solomon, A. (1992). Clinical diagnosis among diverse populations: a multicultural perspective. Families in Society. The Journal of Contemporary Human Services, 73, 371-377.

Urrutia, A. (1994). The development of black feminism. Human Mosaic, 28, 26-35.

Wade, J. (1996). African-American men's gender role conflict: The significance of racial identity. Sex Roles, 34, 17-33. doi:10.1007/BF01544793

Welsing, F. (1970). The cress theory of color confrontation and racism. Washington, DC: C-R Publishers. 